\title{
Impact on procurement and training by research on the interaction design of medical devices
}

\author{
Paul T. Lee \\ Morriston Hospital \\ Swansea, UK \\ paul.lee@wales.nhs.uk
}

[Invited Paper]

\author{
Laura R. Meagher \\ Technology Development \\ Group
}

$\begin{array}{cc}\text { Fife, UK } & \text { London, UK } \\ \text { laura.meagher@btinternet.com } & \text { p.curzon@qmul.ac.uk }\end{array}$

\author{
Paul Curzon \\ Queen Mary University of \\ London \\ London, UK \\ p.curzon@qmul.ac.uk
}

\begin{abstract}
We present a case study of how research can influence practice in the procurement of healthcare technology based on the $\mathrm{CHI}+\mathrm{MED}$ project. $\mathrm{CHI}+\mathrm{MED}$ is concerned with interaction design and the safety of medical devices. It has combined scientific research on underlying human error, and the development of engineering tools and techniques based on this science. It has also included a strong stakeholder engagement strand, aiming to ensure that the research has impact. In particular CHI+MED research has directly informed a $£ 2.5$ million procurement decision at a Welsh health board, leading to safer equipment being bought. It provided the evidence to support one kind of device being rated more highly due to its ease of safe use. Our research is also the basis of a new approach to evidence-based procurement based on proactively analysing error logs of existing devices. The logs are analysed to determine the strengths and weaknesses of devices to provide evidence for future decisions. It has also contributed to a programme to ensure software that helps reduce errors is used. CHI+MED research has also fed into training programmes. Our research is actively preventing patients being unnecessarily harmed and also saving staff time from not having to work with hard to use technology, so ultimately saving money.
\end{abstract}

\section{Categories and Subject Descriptors}

H.1.2 [Information Systems]: User/Machine Systemshuman factors; K.4.1 [Computers and Society]: Public Policy Issues - human safety; J.3 [Life and Medical Sciences]: Medical Information Systems

\section{General Terms}

Design, Human Factors

\section{Keywords}

Safety, Medical Devices, Interaction Design, Procurement, Training

\section{INTRODUCTION}

$\mathrm{CHI}+\mathrm{MED}$ is is a $\mathrm{UK}$ research project investigating how interaction design can help prevent operator error in the use of medical devices of all kinds. CHI+MED researchers have linked with the health service sector to look at device design, usability, human interaction, alarms and helped develop training initiatives and workshops.

In this paper we present a case study of how interaction design research has influenced practice. The second author (Meagher) interviewed a range of external stakeholders to develop case studies about if and how research had actually influenced practice. This paper focusses on one interview drawing out the effect of CHI+MED on procurement and training, particularly around infusion pumps. CHI+MED worked closely with the Morriston Hospital, Swansea and the ABM University Health Board, one of the largest health boards in Wales, throughout the project. In particular researchers on CHI+MED linked closely with the first author (Lee). This case study is based on an interview with Lee to draw out the different kinds of impacts CHI+MED research had actually had on his organisation's practice. Quotes are included from that interview or from follow up clarifications. He is the Medical Devices Training Manager of the ABM University Health Board. Through this link CHI+MED influenced a major procurement decision. He is also a founding member and the Chair of NAMDET (the National Association of Medical Device Educators and Trainers: namdet.org) and the Regional Lead for Wales. This has also led to the project feeding in to training initiatives and the impact being spread beyond the one hospital.

\section{SAFETY AND INFUSION PUMPS}

As far back as 1976 the significance of error in making up drug solutions, calculating rates and administering intravenous infusions was raised at a national level and these errors cannot be underestimated [1]. Nowadays, an abundance of medical infusion devices exist across the UK National Health Service (NHS) to help deliver intravenous drug therapy and fluid replacement. In 2003 (updated in 2010) the UK Department of Health issued landmark guidance to help managers develop strategies for identifying infusion pump variety [4], and help them to address fundamental failures in purchasing strategies, poor equipment allocation, lack of training and highlight the importance of effective risk assessments. 
Progress has been affected by areas of risk and a lack of standardisation [6]. A plethora of software versions and a wide range of infusion pump models, used across all organisations, can have a detrimental effect on safety. Staff are expected to use infusion devices that differ in operation, with consumables that are incompatible with the devices in use. This not only exposes patients to significant risks but nursing staff may be expected to use devices that they are not familiar with. If standardisation is to be adopted, however, making the right procurement decision is even more vital as the consequences of a good or bad decision impact everyone across the organisation rather than just one department.

\section{HOSPITAL PROCUREMENT OF MEDI- CAL DEVICES}

Buying medical equipment for a hospital is complex, involving balancing competing needs such as cost, physical safety, how easy it is to clean and maintain, whether the parts can be bought, dealing with the fact that similar equipment will need to be used in different ways in different parts of the hospital, ability to train staff, and so on. Given all these demands, weighing up how easy a device is to use safely, compared to others, has often been lost. It is often only after incidents happen that this comes to the fore.

CHI+MED research has directly informed a multi-million pound procurement decision at the Welsh health board the project worked with, leading to safer equipment being bought.

"We have better front panels on our devices due to CHI+MED work. We had to change machines ... so in the procurement process we specifically asked for machines with chevron based front panels, not decimal, since CHI+MED research was pointing toward decimal front keyboards being error prone. None have a decimal keyboard anymore; all have a chevron interface. That was a $£ 2.5$ million project and we have machines as a direct result of that $\mathrm{CHI}+\mathrm{MED}$ work. I had the papers and the evidence and we used that in the procurement process and we scored chevron fronts better than others."

This decision was based directly on a multidisciplinary strand of CHI+MED work studying the design of number entry interfaces (see [7] for an overview). It showed that digit keypads are more likely to lead to large mistakes in numbers entered that result in, for example, patients being given dangerous overdoses of drugs. The project provided solid research-based evidence about problems that front-line staff already suspected. Without evidence, however, hospital staff were unable to influence the decisions about what to buy. By asking key questions about the device designs, and then giving solid answers, CHI+MED filled this gap.

"CHI+MED definitely raised lots of questions on design features. ... Some of the early research coming from CHI+MED, like buttons, shape and order - we thought [that design] was wrong and now we know it is wrong ... the robustness of having CHI+MED evidence helps. Thirty years ago we bought equipment at NHS because it looked nice; it was foisted on the workforce; they complained and did work-arounds. People never really looked at the things CHI+MED [looked at]"

CHI+MED has also given a new depth to the way procurement decisions can be made, based, for example, on the use of error logs combined with usability studies of existing machines to analyse the life costs of those products.

\begin{abstract}
"In my organisation, we are using CHI+MED work to measure how expensive products are. We look at the whole process. [For instance we will be] downloading error logs off our machines and we will analyse usability data contrasted to previous machines - that has never been done. ... Up until 5-7 years ago, we never had machines recording (a hangover from when memory chips were expensive in the $80 \mathrm{~s}$ ), whereas now it is cheap and we could track information, so see usability - but very few people were looking at it."
\end{abstract}

CHI+MED research is also the basis of a new approach to evidence-based procurement. The UK Department of Health and regulators only look at errors reported to them. This is the tip of the iceberg. CHI+MED has championed the idea of more post-market review of usability. This involves proactively looking at device use and usability, and analysing error logs of existing devices to determine their strengths and weaknesses to provide evidence for future decisions, not only when mistakes are made, but as a matter of course so that the good can be determined as well as the bad [3]. This understanding can then feed into future decisions. It also means problems can be found before they lead to patients being harmed.

"We are now looking at usability which may or may not lead to error. ... looking at propensity for errors ... has really opened up a can of worms, in a good way"

By spreading understanding about research CHI+MED has the potential to not only save lives but also save money most notably by saving the time of frontline staff, battling with technology that is not well-designed to fit the actual work they do.

\section{STAFF TRAINING}

Research links from procurement have also fed into training:

"Error log reports and outcomes of clinical incidents are shared with trainees and students and we continue to explore their understanding of the importance of data logs and medical device builtin recorders. The public has great faith in these 'black box' recorders, and places an onus on the designers and developers to make safer medical devices for now and the future." 
Another way CHI+MED has supported training is through its public engagement work. An activity originally developed by the CHI+MED team for use as an activity for use at science festivals has been further developed by Lee and used as part of training courses for nurses. It involves giving participants a scenario about a medical incident and asking them to role play different protagonists defending themselves in a discussion about who or what is to blame. This draws out a discussion of blame culture and how it hinders learning. Participants rarely see the device design as being the cause, even though design changes could have prevented the incident, and this is exposed by the activity.

Lee cofounded NAMDET early in the the project. As noted on NAMDET's website, 'The National Association of Medical Device Educators and Trainers was established in 2011 in response to the requests of professionals working in this specialty, who had identified the need for a nationally recognised organisation, operating as a centre of expertise and excellence'. CHI+MED is featured prominently as a key link from the NAMDET website [5] and CHI+MED researchers have given talks at the organisation's meetings. This connection provides a ripple effect further spreading the impact of the research.

The dialogue around research has been two way. For example, training staff had noticed that after being trained on infusion pumps, the transition to the same manufacturer's syringe pumps (or vice versa) was easy for users - when they had the same design of front panels and interface.

\begin{abstract}
"My personal experience from delivering teaching to hundreds of nursing staff is the understanding of the buttons and controls is almost seamless from one device to another (despite the slight layout differences with syringe pump keyboard being longer by design). There is something to be said for having the same controls for both devices $\ldots$ and it is true to say that we are experiencing the luxury of having all our devices standardised across all our wards and departments."
\end{abstract}

The UK National Patient Safety Agency suggested that standardisation of these two devices was a way forward; without any empirical evidence to support this. Nor was it clear to what extent this guidance had been taken up. Lee worked with CHI+MED researchers conducting a UK survey to answer this suggesting that standardisation levels are high [2].

Another issue covered by the survey research is in the use of Drug error reduction software (DERS). This is software included on modern pumps that sits in the background; and stops the user from entering inappropriate numbers, rates and volumes, given the drugs being administered. Even when included in equipment bought usage is low in the UK [2], which may in part be an awareness and training issue. However, working with $\mathrm{CHI}+\mathrm{MED}$ has encouraged Lee to address this for his Health Board. Being involved in the research highlighted that they had the capability and needed to move towards a DERS full roll out. It took several years to get all the hardware in place but the project is about to be launched (in 2015).
"We are also beginning to roll out drug safety software ... and this is another positive move forward that the CHI+MED team have also helped to raise and is still an unresolved issue across the UK ... CHI+MED helped focus our attention ... for sure ..."

\section{SUMMARY}

We have presented a focused case study about the influence on practice of foundational research into the interaction design and safety of medical devices. CHI+MED research has already had a direct impact on the way devices are bought in at least one major UK health board, showing it has potential to have a similar effect more widely.

Published research can have a positive effect on training, procurement and utilisation to help reduce risk, and ensure medical infusion devices remain fit for the 21 st century. The likelihood of impact is increased when researchers engage with stakeholders and their problems both deeply and at an early stage. This case study focussed primarily on infusion pumps. However, the CHI+MED number entry research that the described impact was based on is also relevant to a wide range of medical devices.

This work more generally supports a model of utilising research, showing how working with practitioners from the outset and understanding their problems can lead to research that has deeper impact.

\section{ACKNOWLEDGEMENTS}

This work was funded by EPSRC (EP/G059063/1).

\section{REFERENCES}

[1] Department of Health and Social Security. Addition of drugs to intravenous infusion fluids (The Breckenridge Report). HC(76)9, 1976.

[2] I. Iacovides, A. Blandford, A. Cox, B. Dean-Franklin, P. Lee, and C. J. Vincent. Infusion device standardisation and the use of dose error reduction software: a UK survey. British Journal of Nursing, 23(Sup14):S16-S24, 2014.

[3] P. T. Lee, F. Thompson, and H. Thimbleby. Analysis of infusion pump error logs and their significance for health care. British Journal of Nursing (Intravenous Supplement), 21(8):S12-S20, 2012.

[4] MDA. Infusion systems (v2 updated 2010). Device Bulletin, MDA DB2003(02), 2003.

[5] NAMDET. The national association of medical device educators and trainers: Useful links. http://namdet.org/useful-links / (Last accessed 21 July 2015), 2015.

[6] National Patient Safety Agency. Design for patient safety. A guide to the design of electronic infusion devices. NHS, London, 2010.

[7] P. Oladimeji, H. Thimbleby, P. Masci, and P. Curzon. Issues in number entry user interface styles: Recommendations for mitigation. In Proceedings of the 5th EAI International Conference on Wireless Mobile Communication and Healthcare, October 2015. 